\title{
Memaknai Terjadinya Bencana Alam Merujuk Pada Kajian Tafsir
}

\author{
Moh Rosyid ${ }^{1}$ \\ ${ }^{1}$ Institut Agama Islam Negeri (LAIN) Kudus \\ e-mail: mrosyid72@yahoo.co.id
}

\begin{abstract}
ABSTRAK. Tujuan ditulisnya naskah ini untuk menjadikan al-Quran sebagai tempat bertanya dan mengingat kebesaran Tuhan. Semakin dekatnya manusia pada Tuhan, manusia selalu merawat alam dengan penuh kesadaran. Berbekal data bencana alam dari pesan al-Quran dan pemberitaan koran dengan dengan metode tafsir bi ar-Ra'yi atau al-'aqli dan analisis deskriptif kualitatif dapat dijadikan pelajaran hidup. Bekal dasarnya dengan menyadari bahwa kuasa Ilahi tidak ada duanya karena Dia maha segala-galanya. Bersyukur atas karunia-Nya merupakan modal utama manusia dalam menikmati dan merawat anugerah-Nya. Keramahan dengan memahami esensi anugerah Ilahi berupa alam semesta sehingga menjadi pecinta alam. Keteledoran manusia dalam merawat alam akan menimbulkan musibah/bencana alam. Musibah itu tak selalu dapat diprediksi oleh kecanggihan teknologi dan ilmu pengetahuan dalam hal kapan datang dan kapan berakhirnya bencana alam karena keterbatasan manusia. AlQuran menggambarkan bahwa bencana alam terjadi pada manusia sejak dulu kala. Kejadian itu memiliki ragam makna untuk dijadikan bahan pelajaran hidup.
\end{abstract}

\begin{abstract}
The purpose of paper is to make Al-Quran as a place to ask questions and remember the greatness of God. The closer humans are to God, humans always care for nature with full awareness. Messages of Al-Quran and newspaper coverage with methode tafsir bi ar-Ra'yi atau al-'aqli by qualitative descriptive analysis can be used as a life lesson. It is to realize that Divine power is second to none because He is the Almighty. Human negligence in caring for nature will cause disaster / natural disasters. Disasters are not always predictable by the sophistication of technology and science in terms of when to come and when the end of natural disasters due to human limitations. The Koran illustrates that natural disasters have occurred in humans since the beginning of time. The event has a variety of meanings to be used as material for life lessons.
\end{abstract}

Kata kunci: kewaspadaan, bencana, dan ramah alam

\section{PENDAHULUAN}

Potensi alam Nusantara panjang garis pantainya mencapai 81 ribu km, luas daratannya 1,9 juta $\mathrm{km}$ persegi, luas perairan 3,1 juta $\mathrm{km}$ persegi, dengan jumlah pulau 17.500. Kawasan sekitar lautnya ada 17.504 kepulaun dengan 92 pulau terluar. Posisi Indonesia berada di dua Samudra yakni Samudra Jawa dan Hindia, berada di Benua Asia dan Australia. Terdapat 12 daerah terluar yang berbatasan dengan negara tetangga (1) Pulau Rondo Aceh dengan India, (2) Pulau Berhala Sumatera Utara dengan negara Malaysia, (3) Pulau Nipah Riau dengan negara Singapura, (4) Pulau Sekatung Kepulauan Riau dengan negara Vietnam, (5) Pulau Marore Sumatera Utara dengan negara Filipina, (6) Pulau Miangas Sulawesi Utara dengan negara Filipina, (7) Pulau Baras dan Fanildo Papua dengan negara Palau, (8) Pulau Batek Nusa Tenggara Timur dengan negara Timor Leste, (9) Pulau Dana I dan II Nusa Tenggara Timur 
dengan Australia, dan (10) Pulau Nunukan Kalimantan Timur dengan Malaysia. Kondisi ini sebagai faktor yang menyebabkan beberapa wilayah perairannya menjadi penyebab terjadi konflik yakni untuk segmen Selat Malaka batas ZEE (Zona Ekonomi Eksklusif), untuk segmen Selat Malaka Selatan batas laut wilayah Indonesia-Malaysia, batas laut wilayah di segmen Selat Singapura meliputi perairan seputar Pulau Batam, Bintan, dan Johor (Malaysia), batas ZEE Indonesia-Malaysia untuk segmen Laut China Selatan, dan batas laut wilayah ZEE serta landas kontinen di Segmen Laut Sulawesi.

Kekayaan berupa flora (tumbuhan) dan satwa/fauna (hewan) yang meruah hingga dikenal Peringatan Hari Cinta Puspa dan Satwa setiap tanggal 5 November. Sejak tahun 1993 pasca-KTT Bumi di Brasil 1992 membuahkan Konvensi PBB tentang Keanekaragaman Hayati. Indonesia meratifikasi dalam UU Nomor 5 Tahun 1994 tentang Lingkungan Hidup. Meruahnya kekayaan tersebut maka dikenal mega biodiversity peringkat kedua setelah Brasil karena potensi tumbuhan berbunga $10 \%, 12 \%$ mamalia, $17 \%$ unggas, $16 \%$ reptilia, dan 35 $\%$ ikan. Red Data Book dari Union for Conservation of Nature jumlah flora fauna Indonesia yang musnah ada 128 jenis mamalia, untuk burung ada 104 jenis, jenis ikan ada 60, dan 590 jenis tanaman. Eksisnya ragam hayati diwujudkan dengan konservasi yakni tindakan berbudaya secara sadar pentingnya melestarikan ciptaan Tuhan dengan melindungi secara teratur untuk mengantisipasi rusak dan musnahnya sumber daya alam.

Hanya saja, di balik melimpahnya kekayaan alam tersebut, Indonesia rentan dilanda bencana alam. Bila hanya mengandalkan ilmu dan teknologi, bangsa dunia, termasuk Indoneesia tidak mampu menyikapi. Ketidakmampuan ini bila tidak diimbangi dengan upaya memohon keagungan sang Pencipta maka terjadi frustasi dalam merawat sumber alam. Dengan demikian, agama diperankan sebagai media bersandar untuk mengurangi tensi psikis dengan menggali hikmah dari bencana. Upaya dapat dilakukan dengan (1) mendekatkan diri pada Tuhan setiap waktu dengan beribadah dan berdoa, (2) mengatisipasinya dengan melengkapi alat yang canggih di bidang mitigasi bencana, (3) membekali generasi muda memahami dinamika alam melalui pendidikan.

Konsep agama menandaskan bahwa kemungkinan terjadinya bencana (1) ujian/cobaan karena keimanan atau kekafiran, (2) sanksi/hukuman karena kecerobohan, (3) menuai hikmah setelah diuji bila menghayati. Hal ini sangat tergantung kesadaran diri setelah perilaku pribadi atau kelompok masing-masing instropeksi secara individu atau kolektif. Kandungan al-Quran tentang bencana perlu ditelaah dengan pendekatan ilmu tafsir agar sikap dan respon bila menerima musibah mengedepankan kesabaran dan kesadaran sebagai manusia yang beragama.

Bencana bermanfaat bagi manusia di bidang ilmu pengetahuan, sebagaimana tsunami di Aceh. Pakar tsunami menemukan realitas yang sebelumnya diyakini pergerakan lempeng berusia muda bisa menimbulkan gempa besar, ternyata juga bisa terjadi di zona penunjaman oblik (melengkung) sebelumnya tidak banyak dikenal. Dampak kerusakan akibat tsunami bukan hanya kecepatan gelombang $400 \mathrm{~km}$ per jam, tetapi kemampuan membawa material bangunan/tanaman yang mematikan. Bencana disikapi pemimpin/penguasa dengan penegakan hukum bagi pelanggar tataruang, membentuk komunitas tanggap bencana, membenahi tata ruang dengan peta daerah bencana karena daerah resapan air telah beralih fungsi, bantaran sungai dijadikan hunian, pembangunan hunian berada di atas zona patahan gempa dan di pesisir pantai yang rentan tsunami. Solusinya merehabilitasi lahan resapan yang menjadi hunian dan lainnya, menghijaukan hutan gundul akibat perambahan agar rimbun. 
Mengapa ditimpa bencana? Bagi ilmuwan muslim, Al-Quran untuk dijadikan bahan kajian atas musibah alam yang menimpa generasi masa lalu.

Ruang lingkup penelitian agama khususnya Islam, menurut S. Praja terdiri atas (1) penelitian terhadap Quran dan hadis yang bertujuan mengembangkan ilmu tafsir dan ilmu hadis, (2) penelitian pemikiran Islam yakni upaya umat Islam dalam memahami sumber utama ajaran Islam sebagai penunjang pengembangan filsafat Islam dan ilmu kalam, (3) penelitian sejarah umat Islam dan aplikasi ajaran dan pemikirannya dalam kehidupan individu, keluarga dan masyarakat bertujuan untuk mengungkapkan perkembangan kebudayaan umat Islam serta pranata sosial yang pernah ada, berkembang, dan memiliki potensi untuk dikembangkan pada masa kini dan mendatang. Penelitian semacam ini membantu pengembangan ilmu fikih, ketatanegaraan dan pemerintahan, pendidikan, politik, dsb., (4) penelitian tentang bagaimana sumber maupun ajaran agama, pemikiran umat, dan penafsirannya dikomunikasikan pada publik. Penelitian ini dapat membantu pengembangan ilmu dakwah/komunikasi, (5) penelitian bahasa Arab dan bahasa lain yang dominan dalam sejarah perkembangan Islam dapat membantu pengembangan ilmu agama secara umum, dan (6) penelitian ajaran Islam dan aplikasinya dalam masyarakat tertentu hingga kini masih 'hidup'. ${ }^{1}$ Penelitian ini bersifat praktis, tetapi jika diteliti dengan cermat dapat melahirkan teori keislaman baru. Penelitian semacam ini dilakukan dalam lingkungan 'lokal' umat Islam, seperti keislaman masyarakat Indonesia, dsb.

Naskah ini memaparkan kandungan al-Quran tentang bencana alam. Hasilnya untuk bekal bagi pembaca untuk menyadari bahwa masa lalu pada kaum tertentu telah ditimpa musibah sehingga perlu memahami agar tidak menjadi korban berikutnya.

\section{METODOLOGI}

Para ilmuwan tafsir mendalami kandungan al-Quran dengan ragam metode (1) tafsir bi alma'tsur yakni menafsirkan al-Quran dengan menelusuri jejak generasi masa lalu hingga era Nabi SAW, (2) tafsir bi ar-Ra'yi atau al-'aqli, yakni mufasir berijtihad menerangkan maksud ayat demi ayat secara garis besar atau terinci berbekal ilmu bahasa Arab (nahwu, shorof, balaghah, fiqih lughoh), ilmu qiroah, ulumul quran dan ulumul hadis, (3) kontekstual atau historis yakni memahami kehidupan Nabi SAW dan adat istiadat di mana Nabi SAW hidup, (4) hermeneutik, yakni mendapat kesimpulan makna memahami konteks apa yang menyebabkan ditulisnya ayat, komposisi teks ayat, dan keseluruhan teks ayat sebagai pandangan hidup. Naskah ini dengan metode tafsir bi ar-Ra'yi atau al'aqli.

Adapun sistematikanya dikenal (1) sistematika tablili yakni memahami aspek bahasa, korelasi antar-ayat, aspek makna, dan hukum yang terkandung, (2) tartib nuæuli, yakni berdasarkan kronologi turunnya ayat demi ayat, (3) maudhu'i, yakni menelaah tema tertentu. ${ }^{2}$ Naskah ini menggunakan sistematika maudhu'i yang menelaah tema tertentu, yakni ayat alQuran yang menggambarkan bencana alam masa lalu. Klasifikasi produk tafsir dapat dikategorikan tiga hal, (1) tafsir tradisional dengan menggunakan pokok bahasan tertentu sesuai minat dan kemampuan mufasir, (2) tafsir reaktif, yakni reaksi pemikir modern atas sejumlah hambatan yang dialami orang yang hambatannya dianggap dari al-Quran, dan (3)

\footnotetext{
${ }^{1}$ Juhaya S Praja. 2002. Filsafat dan Metodologi Ilmu dalam Islam dan Penerapannya di Indonesia. Teraju: Jakarta, hlm.14.

${ }^{2}$ Yunahar Ilyas. 1997. Feminisme dalam Kajian Tafsir Al-Quran Klasik dan Kontemporer. Pustaka Pelajar: Yogyakarta, hlm. 22-28.
} 
tafsir holistik, yakni tafsir yang menggunakan seluruh metode penafsiran dan mengaitkan dengan berbagai persoalan hidup. ${ }^{3}$ Naskah ini kategori tafsir tafsir tradisional dengan menggunakan pokok bahasan tertentu, yakni ayat-ayat yang memaparkan terjadinya bencana alam.

Dari aspek tipe kajian tafsir terpilah tafsir tablili (tajzi’i), tafsir maudhu'i (taubidi). Menurut ukuran waktu terpilah tafsir era Nabi dan sahabatnya, era tabi'in, dan era kodifikasi. Naskah ini menggunakan aspek tipe tafsir maudhu'i dan kajian era kodifikasi. Berdasarkan pijakan waktu terpilah tafsir klasik (tafsir bahasa, tafsir riwayat, tafsir fikih, tafsir tasawuf, tafsir filsafat, dan tafsir akidah), tafsir modern (tafsir ilmi, tafsir reformis (ishlahi), dan tafsir sosial (ijtima`). Naskah ini kategori tafsir modern/ilmi.

Berdasarkan tema, dipilah atas tafsir ijmali, tablili, muqorin (membandingkan antar-ayat atau antar-tafsir), dan tafsir maudhu'i (urutan tema kajian). Tafsir maudhu'i dibagi dalam tiga tipe, yakni menggunakan al-Quran sesuai tertib mushaf dan disusun sesuai tema kajian, menggunakan al-Quran sesuai tema surah, dan menggunakan al-Quran sesuai tertib nu₹ul. ${ }^{4}$ Naskah ini berdasarkan tema muqorin tentang jati diri manusia perdana di bumi. Menafsirkan al-Quran dapat pula dilakukan dengan pendekatan historis dengan tipe memahami pesan inti ayat, mengeksplorasi relasi antara wahyu al-Quran dan realitas kehidupan, dan hubungan teks al-Quran dengan teks al-Quran lainnya. ${ }^{5}$ Jadi, naskah ini mendalami aspek tema surat tentang manusia perdana di bumi. Analisis yang digunakan dalam Naskah ini adalah kontens analisis.

Kajian keislaman (islamic studies) merupakan disiplin ilmu yang membahas Islam dalam hal ajaran, kelembagaan, sejarah, dan kehidupan umatnya. ${ }^{6}$ Penelitian agama di antaranya mencari kebenaran substansi dalam ajaran agama. ${ }^{7}$ Untuk memahami kandungan kitab suci, ada tiga pendekatan, yakni mengenali sifatnya, mengenali peringkat pesan yang terkandung di dalamnya, dan menggali isinya dengan metode tafsir. ${ }^{8}$ Al-Quran sebagai sumber ajaran Islam di dalamnya di antaranya membahas ilmu 'am dan khas. ${ }^{9}$ Kekhosan kajian dalam naskah ini dalam hal bencana alam yang digambarkan dalam al-Quran. Untuk memahaminya, dibahas dalam naskah ini.

\section{TEMUAN}

Bencana yang diderita manusia dikenal dengan istilah musibah. Musibah dari kata ashaba, yushibu, mushibah secara harfiyah bermakna sesuatu yang menimpa orang dan tak menyenangkan atau menderita kemalangan. Dalam catatan sejarah, menurut ilmuwan bidang kebumian, bumi/daratan di dunia semula satu (Pangaea) dari bahasa Yunani dari kata pang:

\footnotetext{
${ }^{3}$ Abdul Mustaqim. 2008. Paradigma Tafsir Feminis Membaca Al-Quran dengan Optik Perempuan. Logung Pustaka: Yogyakarta, hlm. 38-39.

${ }^{4}$ Aksin Wijaya. 2016. Sejarah Kenabian dalam Perspektif Tafsir Nuzuli Mubammad Izzat Darwazah. Mizan: Bandung, hlmn.44.

${ }^{5}$ Sahiron Syamsuddin. 2016. Tipologi Penafsiran Historis atas Al-Quran dalam Sejarah Kenabian dalam Perspektif Tafsir Nuzuli Mubammad Irzat Darwazah. Mizan: Bandung,hlm.16.

'Jamali Sahrodi. Metodologi Studi Islam Menelusuri Jejak. Historis Kajian Islam ala Sarjana Orientalis. Pustaka Setia: Bandung, 2008, hlm.37.

${ }^{7}$ Imam Suprayogo dan Tobroni. Metodologi Penelitian Sosial-Agama. Rosda Karya: Bandung, 2001, hlm.15. ${ }^{8}$ Syahrin Harahap. 2000. Metodologi Studi dan Penelitian Ilmu-Ilmu Ushuluddin. Rajawali: Jakarta, hlmn.11.

${ }^{9}$ Nasr Hamid Abu Zaid. 2001. Tekstualitas Al-Quran Kritik terhadap Ulumul Quran. LKiS: Yogyakarta, hlm. 263.
} 
dunia dan gaia: bumi. Pangaea terdiri benua, pulau besar dan kecil, teluk, dan pantai. Pangaea merupakan bumi asal mula ada pada zaman Permain, sekitar 250 juta tahun lalu yang pecah sekitar 225 juta tahun lalu menjadi dua bagian besar yaitu Laurasia di utara dan Gondwanaland di selatan. Lahirlah teori 'Pengapungan Benua' (Continental Drift) dilengkapi teori Tektonik Lempeng. Kedua teori lahir dari pergulatan dan perdebatan sengit antardisiplin ilmu (paleontologi/pengkaji fosil, seismologi/pengkaji gempa bumi). Sejak abad ke-16 terjadi pergulatan antara para ilmuwan, agamawan, dan filosof untuk mencari jawaban atas pertanyaan: mengapa bumi terus dilanda bencana yang menyebabkan tercabiknya daratan hingga menjadi wilayah pecahan? Menurut ilmuwan karena proses alami atau imbas negatif perilaku manusia pada alam.

Al-Quran mengingatkan manusia, dalam surat Ar-Rum:41 "terjadinya kerusakan di darat dan laut akibat ulah manusia", An-Nisa:79 "bencana menimpa manusia karena kesalahannya", Al-A'raf:165 "Allah menimpakan siksa bagi yang zalim”, At-Taubah:26 "Allah menjatuhkan bencana pada yang ingkar sebagai balasan". Bila manusia tak diuji bencana, mereka sombong, sebagaimana tertuang dalam Q.s Huud:10 "tak ada bencana padaku". Apa yang kita lakukan? Huud:11 "sabar atas bencana, kerjakan amal salih, (semoga) diberi ampun dan pahala yang besar dari-Nya". Pesan Ali Imran:137 Sungguh telah berlalu sebelum kamu sanksi Tuhan sepert petaka, bencana yang menimpa pendusta pada utusan-Nya. Hiduplah di bumi dan perhatikan dampak orang yang mendustakan utusan-Nya. Surat Al-An'am:11 hiduplah di bumi, perhatikan akibat orang yang mendustakan. Ar-Rum: 9 apakah manusia tidak hidup di bumi dan menyadari dampak bagi generasi sebelumnya.

\section{DISKUSI}

\section{Alquran dan Pendokumentasian Potensi Alam dan Bencananya}

Al-Quran sebagai bahan renungan manusia atas kuasa Ilahi. Pesan An-Naml: 88 "Kamu melihat gunung dan menyangkanya tetap di tempatnya? Gunung berjalan sebagaimana berjalannya awan. Allah membuatnya kokoh. Pesan surat Al-Hadid:1, al-Hasyr:1, AshShof:1, Al-Jumuah:1 "Semua yang ada di langit dan di bumi bertasbih pada Allah", pesan surat ar-Ra'du:2 Allahlah yang meninggikan langit tanpa tiang. Allah bersemayam di atas 'Arsy mengendalikan matahari dan rembulan, keduanya beredar pada masa yang ditentukan. Pesan ayat menandakan, kejadian di alam hanya skenario Allah. Hamba haruslah waspada, yang terjadi di alam ini kehendak-Nya. Tetapi, menusia wajib berupaya dengan kesadaran yang tinggi.

Alam pun rentan ditimpa bencana. Banjir bandang masa lalu terdokumentasikan dalam al-Quran, sebagaimana era Nabi Nuh dalam al-Ankabut:14; banjir kaum Saba', Q.s Saba':15-19; Topan kaum 'Ad era Nabi Hud, Q.s: Qaaf:13; kaum Madyan era Nabi Syu'aib dengan hawa panas tinggi Q.s At-Taubah:70, al-Hijr:78, Thaha:40 dan al-Haj:44. Gempa bumi era Nabi Luth Q.s Asy-Syuara:160, an-Naml:54, al-Hijr:67, al-Furqon:38, Qaf:12 dan al-Baqarah:155-156.

Di tengah kecanggihan manusia 'mengelola' teknologi dan lupa pada Tuhan, cobaan sering menghampiri, sebagaimana tsunami di Jepang 2011 yang menelan kerugian ekonomi hingga Rp 2.100 triliun (APBN Indonesia 2014 hanya Rp 1.842 triliun) karena kerusakan sarana dan prasarana fisik (perumahan, jalan, pelabuhan), prasarana sosial (listrik, air). Belum lagi kerugian industri asuransi. Warning (peringatan) terjadinya bencana 
sejak dulu hingga kini sebagai pertanda bahwa manusia lemah dalam menghadapi kuasa Ilahi sehingga perlu kehati-hatian dalam hidup. Ramah terhadap lingkungan dan berdoa merupakan kekuatan manusia dalam hidup.

Ada satu atau lebih di antara kemungkinan terjadinya bencana bagi manusia (1) ujian/cobaan karena keimanan atau kekafiran, (2) sanksi/hukuman karena kesalahan, (3) menuai hikmah setelah diuji bila menghayati. Hal ini sangat tergantung kesadaran diri setelah perilaku pribadi atau kelompok masing-masing instropeksi secara individu atau kolektif. Al-Quran mengingatkan kita Ar-Rum:41 "terjadinya kerusakan di darat dan laut akibat ulah manusia", An-Nisa:79 "bencana menimpamu karena kesalahanmu", AlA'raf:165 "Allah timpakan siksa bagi si zalim", At-Taubah:26 "Allah timpakan bencana pada si ingkar sebagai balasan". Bila manusia tak diuji bencana, mereka membusungkan dada, sebagaimana disindir Allah dalam Q.s Huud:10 "tak ada bencana padaku". Apa yang kita lakukan? Huud:11 "sabar atas bencana, kerjakan amal salih, (semoga) diberi ampun dan pahala yang besar dari-Nya". Pesan Ali Imran:137 Sungguh telah berlalu sebelum kamu sanksi Tuhan sepert petaka, bencana yang menimpa pendusta pada utusan-Nya. Hiduplah di bumi dan perhatikan dampak orang yang mendustakan utusan-Nya. Surat AlAn'am:11 hiduplah di bumi, perhatikan akibat orang yang mendustakan. Ar-Rum: 9 apakah manusia tidak hidup di bumi dan menyadari dampak bagi generasi sebelumnya.

\section{Merawat Alam Berpijak pada Al-Quran}

Anugerah Ilahi yang tak ternilai di antara anugerah lainnya adalah air. Air dihadirkan Allah SWT di bumi untuk kehidupan manusia agar dimanfaatkan sesuai kebutuhan. Pada saat tertentu, air berperan antagonis bagi manusia seperti banjir dan di saat lain menjadi 'nyawa' bagi manusia. Tetapi perawatan atas sumber air tidak mendapat perhatian meski berdalih pembangunan (pengeprasan tebing, penggundulan hutan, dan penyedotan air bawah tanah melebihi kapasitas). Filosofi air bagi kehidupan adalah memediasi residu manusia dari hulu hingga hilir. Lihatlah, air hujan yang diterima bumi, mengalir ke parit, ke sungai dan berakhir di samudra membawa segala kotoran yang diciptakan manusia. Air diberi tugas Ilahi tak pernah mengeluh, tapi konsisten dengan peran dan tugasnya karena kodrat-Nya, meski manusia lebih sering menistakan air dengan cara yang tak disadari, seperti pemborosan dalam berwudlu atau mandi dan tak membuat area resapan air, apalagi merawat sumber air.

Al-Quran mendeskripsikan fungsi air dalam berbagai bentuk (1) rezeki; al-Baqarah 22 "Allah membuat hujan yang menumbuhkan buah-buahan".(2) pesan moral; adzDzariyat 20-21 "peristiwa yang berkaitan dengan bumi dan diri manusia terdapat pelajaran berharga bagi manusia bila berpikir dan menyadarinya".(3) sumber kehidupan manusia; alAnbiyak 30 "dari air Allah jadikan segala sesuatu yang hidup". Adapun karakter air (1) dinamis karena jika air berhenti/tak mengalir akan dijadikan sarang nyamuk dan sejenisnya sehingga menjadi wahana penangkaran bibit penyakit bagi manusia. (2) tak bisa dipecah atau dihancurkan bahkan akan menenggelamkan benda/barang yang kokoh, seperti tsunami dan banjir bandang. (3) taat pakem. Air selalu menaati aturan kosmos, mengalir pada dataran tinggi ke rendah. Bila manusia mengiblat pakem ini akan selamat. Allah SW'T mengingatkan dalam Ar-Rum:41-42 "kerusakan di darat dan di laut akibat ulah manusia...." “...telaahlah dampak kehidupan generasi masa lalu.....”. Ayat ini untuk kita jadikan pelajaran hidup. Anugerah kehidupan yang diterima manusia dari-Nya tak 
terhitung, lantas Allah mengingatkan berkali-kali dalam Ar-Rahman "nikmat Tuhanmu yang mana yang kau dustakan? Air pada saat tertentu anugerah, pada saat yang lain menjadi petaka karena manusia melupakan kodrat dan iradat-Nya.

Nikmat alam yang eksotis (keindahan) perlu belajar dalam merawatnya sebagaimana dilakukan penduduk Papua dan Ternate berupa kearifan lokal dikenal sasi nggama yakni larangan (buka sasi) dengan upacara adat bila mengambil biota laut berupa lola, teripang, dan batulaga selama 11 bulan dalam setahun, memanen hanya antara Maret dan Mei. Bila dilanggar membayar denda dan sanksi tererat pengucilan dan teguran alam, tradisi didukung peraturan daerah. ${ }^{10}$ Begitu pula warga Desa Kuen Heun, Kecamatan Kupang Barat, Kabupaten Kupang, NTT mempertahankan adat Lilifuk untuk melindungi kelestarian ikan di wilayahnya. Adat membatasi nelayan menangkap ikan pada waktu tertentu guna memberi kesempatan ikan untuk berkembang biak dan mencegah kelangkaan ikan. Ikan biasanya setahun hanya ditangkap setiap enam bulan sekali atau setahun dua kali dan hari penangkapan hanya ditentukan sehari dengan cara diumumkan pada warga. Pada hari yang ditentukan, semua warga berkumpul untuk menangkap ikan di satu lokasi kolam ditandai pembatas berupa tali, gabus, dan botol yang mengapung. Alat tangkap ikan yang digunakan hanya berupa serok. Penangkap ikan datang dari warga sekitar dan warga yang jauh dari lokasi penangkapan. Setiap warga yang menangkap membayar retribusi Rp 5.000 untuk kas desa. Warga Desa Kuen mata pencaharian utamanya adalah bertani di ladang kering antara lain dengan menanam jagung, kacang tanah, dan ubi. ${ }^{11}$ Papua kini sering bergolak meski ada Freeport, perusahaan emas raksasa dunia asal AS menguasai saham awalnya 90,64\% saham Freeport Indonesia. Pada 7 November 2013 Freeport melepas 15,64 \% saham, 10,64 persen dijual pemerintah RI. Freeport menyetorkan pada pemerintah RI per semester I 2013 dengan royalti 56 juta dollar AS, PPh badan 193 juta dollar AS, dan pajak lainnya 97 juta dollar AS. ${ }^{12}$

Pemetaan Badan Nasional Penanggulangan Bencana pascatsunami Aceh 2004 bahwa di 16 kabupaten (Aceh hingga Jawa Timur) rawan terjadi tsunami. Riset Widjo Kongko, Rahman Hidayat, dan Dinar Catur Istiyanto pada 2006-2009 kawasan Indonesia menyimpan potensi tsunami. Hal ini dipicu kawasan gempa dan letusan gunung api di zona gelap gempa (seismic gap) yakni kawasan patahan yang minim/kosong data dibandingkan titik gempa di sekitarnya. Hasil riset ahli tsunami LIPI Danny Hilman, seismic gap tersebar di 9 kawasan: sekitar Pulau Simeleu, barat daya Pulau Siberut, sekitar Kepulauan Mentawai, Selat Sunda, selatan Jawa Tengah, selatan Bali, Selat Sumba, Sorong, Laut Halmahera, dan Laut Maluku rentan gempa berkekuatan 8 SR penyebab tsunami. Juga terdapat zona potensial tinggi tsunami (ZPTT) karakternya serupa seismic gap. ZPTT terekam di Palung Banda pada 1852, zona subduksi Pulau Seram pada 1674, dan Flores-utara Sumbawa pada 1820. Kawasan Sangihe-Halmahera dan zona subduksi utara Sulawesi belum terdeteksi karena minim data rentan bahaya karena dekat patahan Filipina. Rekaman tsunami terjadi pada beberapa gunung: Krakatau 1883, Tambora 1815, Rokatenda 1928, Raung 1889, Awu 1856 dan 1892, Gamkonora 1673, dan Gamalama 1871. Yang belum terdeteksi tapi rentan tsunami Gunung Makian di Halmahera, Banda

${ }^{10}$ Kompas, 30 Oktober 2013.

${ }^{11}$ Kompas, 4 November 2013.

12 Jawa Pos, 8 November 2013. 
Api di Kepulauan Banda, Karangetan di Sangihe, Una-Una di Teluk Tomini, Weh di Aceh. ${ }^{13}$

Benteng Kuta Lubok, Aceh berada di tepi laut Desa Lamreh, Kecamatan Krueng Raya, Aceh Besar yang berhadapan langsung dengan Selat Malaka. Pada masa lalu, daerah itu pernah menjadi pusat keramaian di Aceh. Riset Nazli Ismail, M.Yanis, dan Gunawati dari Jurusan Fisika Universitas Syiah Kuala Aceh yang memakai elektromagnetik berhasil merekonstruksi ukuran benteng seluas $45 \mathrm{~m}$ x $100 \mathrm{~m}$, jejak jalan dalam benteng dan makam kuno. Keragaman pecahan tembikar yang ditemukan di lokasi menunjukkan, kawasan itu pernah menjadi persinggahan para pedagang dari Tiongkok dan Vietnam. Di kawasan yang sama, $500 \mathrm{~m}$ dari Benteng Kuta Lubok, ada reruntuhan Benteng Inong Bale. Benteng Kut Lubok dan Inong Bale diperkirakan sisa peninggalan Kerajaan Lamuri era abad ke-9. Lamuri lenyap karena tsunami pada tahun 1300 dan pertengahan 1450. Jejak tsunami terulang berkali-kali ditemukan Ismail dkk melanda Pantai Aceh. Di Lhok Cut dan Ujung Batee Kapal, Kecamatan Mesjid Raya. Ismail dkk menemukan sisa bangunan kuno terkubur pasir (hingga kedalaman $380 \mathrm{~cm}$ ), keramik, dan sumur kuno. Setiap temuan artefak ada lapisan endapan tsunami. Di Goa Pantai Lhong, Aceh Besar, tim menemukan 10 lapis jejak tsunami kuno, yakni jejak tsunami tahun 2004, 2.800 tahun lalu, 3.300 tahun lalu, 5.400 tahun lalu, dan 7.500 tahun lalu. Kerajaan Samudera Pasai di pesisir timur Aceh sekitar aad ke-13 diduga muncul setelah kekuatan Lamuri meredup karena bencana. Tsunami Aceh tahun 2004 diduga menewaskan 150.000 warga Aceh. ${ }^{14}$

Merawat kapasitasnya sebagai khalifah di bumi merupakan kewajiban manusia berbekal ilmu, pengetahuan, teknologi, dan sikap beragama.

\section{KESIMPULAN}

Bencana alam yang terjadi dan menimpa pada diri manusia memiliki ragam makna. Pertama, di balik meruahnya anugerah Tuhan pada manusia berupa alam beserta isinya, bila tidak ditangani dengan ramah dan manusia menjauh dari sifat syukur pada-Nya maka ancaman bencana akan menghadang manusia. Kedua, berbekal ilmu pengetahuan dan keimanan, upaya untuk merawat alam merupakan keharusan di mana pun manusia berada. Ketiga, datangnya musibah yang menimpa manusia tidak selalu terprediksi oleh ilmu pengetahuan, misalnya tsunami, gempa bumi. Ada pula musibah karena ulah manusia seperti penggundulan hutan hingga terjadi longsor. Maknanya, kesigapan dan kesiapan mental merupakan modal diri manusia tatkala hidup bersama alam dan dinamikanya. Keempat, kekuatan utama manusia yang tertinggi adalah dikabulkannya doa oleh Tuhan di kala suka dan duka dalam kehidupan. Bila keempat poin ini dipegang teguh oleh manusia, maka sikap waspada dan bersyukur dengan karunia Ilahi atas alam beserta isinya (yang dijadikan sandaran hidup) selalu menjadi denyut nadi manusia. Sikap ini mengurangi karakter sombong manusia tatkala 'berkuasa' bersama alam sebagai tempat berpijak dan tempat menjunjung kehidupannya.

Al-Quran telah menggambarkan bahwa musibah telah diderita manusia sejak dulu kala. Hal ini sebagai pertanda bahwa manusia lemah dan kuasa Ilahi adalah segala-galanya.

${ }^{13}$ Cornelius Helmy. Pemicu Tsunami Terlupakan. Kompas, 31 Juli 2013, hlm.14.

${ }^{14}$ Kompas, 11 September 2014. 


\section{REFERENSI}

Harahap, Syahrin. Metodologi Studi dan Penelitian Ilmu-Ilmu Ushuluddin. Rajawali: Jakarta. 2000.

Helmy, Cornelius. Pemicu Tsunami Terlupakan. Kompas, 31 Juli 2013.

Ilyas, Yunahar. Feminisme dalam Kajian Tafsir Al-Quran Klasik dan Kontemporer. Pustaka Pelajar: Yogyakarta. 1997.

Mustaqim, Abdul. Paradigma Tafsir Feminis Membaca Al-Quran dengan Optik Perempuan. Logung Pustaka: Yogyakarta. 2008.

Praja, S. Juhaya. Filsafat dan Metodologi Ilmu dalam Islam dan Penerapannya di Indonesia. Teraju: Jakarta. 2002.

Suprayogo, Imam dan Tobroni. Metodologi Penelitian Sosial-Agama. Rosda Karya: Bandung, 2001.

Syamsuddin, Sahiron. Tipologi Penafsiran Historis atas Al-Quran dalam Sejarah Kenabian dalam Perspektif Tafsir Nuzuli Muhammad Izzat Darwazah. Mizan: Bandung. 2016.

Sahrodi, Jamali. Metodologi Studi Islam Menelusuri Jejak Historis Kajian Islam ala Sarjana Orientalis. Pustaka Setia: Bandung, 2008.

Wijaya, Aksin. Sejarah Kenabian dalam Perspektif Tafsir Nuzuli Mubammad Izzat Darwazah. Mizan: Bandung. 2016.

Zaid, Nasr Hamid Abu. Tekstualitas Al-Quran Kritik terhadap Ulumul Quran. LKiS: Yogyakarta. 2001. 